\title{
HOMENAGEM A FRIEDRICH ENGELS PELOS SEUS 200 ANOS DE NASCIMENTO
}

DOI: http://dx.doi.org/10.9771/gmed.v12i3.42930

\author{
Maria de Fatima Rodrigues Pereira ${ }^{1}$ \\ Pedro Leão da Costa $\mathrm{Neto}^{2}$ \\ Rodrigo Castelo ${ }^{3}$
}

Os duzentos anos de nascimento de Friedrich Engels é uma particular ocasião para lembrar a importância deste grande pensador do Oitocentos. Para além da sua indissociável amizade e cooperação com Karl Marx, foi precursor da Crítica da Economia Política com o seu "genial esboço", investigador das condições de vida da classe operária, publicista, estudioso das Ciências da Natureza e da origem das instituições sociais, autor de grandes obras de sistematização e difusão do marxismo e editor e divulgador da obra de seu grande camarada. Engels foi, acima de tudo, um militante e dirigente revolucionário. Estas são apenas algumas facetas deste incansável pensador e revolucionário comunista.

Entretanto, esta comemoração não poderia ocorrer em um momento mais adverso, não só pela pandemia que já deixou mais de um milhão e setecentos mil mortes e um incontável número de sequelas e sofrimentos, mas também por uma grande ofensiva reacionária e obscurantista em escala planetária. E esta é mais uma razão para lembrarmos a obra deste grande defensor do pensamento científico.

Apesar das condições adversas, ao longo de todo o ano de 2020, foram inúmeras as celebrações a respeito do bicentenário de nascimento de Friedrich Engels. Todas reconhecem, ao seu modo, a grandeza, o valor e a atualidade do trabalho militante e teórico de Engels na construção do movimento socialista internacional e do marxismo. No campo editorial, foram publicados livros da própria lavra de Engels, como Dialética da natureza (ed. Boitempo), e outros assinados conjuntamente com seu camarada Karl Marx, como Cartas sobre o capital e Nova Gazeta Renana (ed. Expressão Popular) e Escritos sobre a guerra civil americana (ed. Aetia e Peleja). Além desses impactantes lançamentos, foi publicada uma das melhores biografias do nosso homenageado, a escrita por Gustav Mayer em 1936 e só agora publicada no Brasil (ed. Boitempo), com apresentação e notas (que enriquecem a produção) de José Paulo Netto. A editora Anita Garibaldi também participou das comemorações e lançou a coletânea de artigos Friedrich Engels 200 anos: ensaios de teoria social e política, organizado por Theófilo Rodrigues. E ainda é aguardada a publicação dos Escritos militares de Friedrich Engels, um projeto organizado por Gabriel Landi, Euclides Vasconcelos e João Carvalho em vias de lançamento da editora Baioneta e do Instituto Caio Prado Jr.

Vale registrar que a língua portuguesa ganhou novas publicações de Engels em terras lusitanas. A editora Avante!, do Partido Comunista Português, deu continuidade na sua biblioteca do marxismoleninismo com a publicação de quatro obras engelsianas - $A$ ideologia alemã (primeiro capítulo escrito conjuntamente com Marx), Princípios básicos do comunismo, Revolução e contra-revolução na Alemanha e Anti-Dühring, que ganhou uma tradução inédita realizada por José Barata-Moura. Antes disso, em 2018, o marxista 
português já tinha publicado pela mesma editora uma nova tradução de Ludwig Feuerbach e a saída da filosofia alemã clássica, acompanhado de um rico aparato de introdução, notas e conclusão.

Algumas revistas inscritas no campo do marxismo prestaram homenagens à Engels. A Margem esquerda, organizada pela Boitempo, publicou no seu número 35 um belo e conciso texto escrito por Astrojildo Pereira em 1945, precedido por uma introdução de João Quartim de Moraes. A Crítica Marxista, originária das ciências sociais e humanas da Universidade Estadual de Campinas (Unicamp), publicará em seu número 51 um artigo do mesmo João Quartim de Moraes sobre "O trabalho na Dialética da Naturęa" e uma apresentação da citada tradução de Barata Moura do livro Ludwig Feuerbach e a saída da filosofia alemã clássica. Verinotio, revista online de filosofia e ciências humanas, sob coordenação do curso de Serviço Social do campus Rio das Ostras (Puro) da Universidade Federal Fluminense (UFF) e do grupo de pesquisa Marxologia: filosofia e estudos confluentes da Universidade Federal de Minas Gerais (UFMG), organizou um extenso dossiê sobre o bicentenário de Engels no seu volume 26, número 2. São, ao todo, nove artigos de comentadores e três de Engels traduzidos para o português, sendo um deles uma nova versão do clássico "Esboço para uma crítica da economia política", desta vez traduzido por Ronaldo Vielmi Fortes.

A internet também foi palco de celebrações do bicentenário de Engels. Por conta da crise sanitária ocasionada pela pandemia da Covid-19, editoras e grupos acadêmicos de estudos e pesquisas realizaram atividades online gratuitas, evitando aglomerações e seguindo o bom senso da ciência e da proteção da vida humana. No canal da TV Boitempo, entre os dias 23 a 28 de novembro, foi organizado mais um curso livre Marx-Engels. Desta vez foram 5 aulas e um debate com grandes especialistas na obra de Engels, tais como Alysson Mascaro, José Paulo Netto, Maria Lígia Quartim, Marília Moschkovich, Osvaldo Coggiola, Ricardo Antunes, Sabrina Fernandes e Virgínia Fontes. No mesmo período de novembro, o grupo de pesquisa Marxismo e filosofia, coordenado pelo professor Benedito Caires Araújo da Universidade Federal do Sergipe (UFS), também promoveu uma extensa programação, com mesas sobre cristianismo primitivo, feminismo e marxismo, história e militarismo, assim como sobre diversas publicações engelsianas ( $A$ situação da classe trabalhadora na Inglaterra, Anti-Dühring, Nova Gazeta Renana e Socialismo utópico e socialismo científico). Do seminário 200 anos Friedrich Engels, participaram Ana e Vera Cotrim, Camila Moreno, Euclides Vasconcelos, José Paulo Netto, Maynara Santiago, Osvaldo Coggiola, Osvaldo Maciel, Rodrigo Medina, Sofia Manzano, dentre tantas outras e outros. No mesmo mês de novembro foi realizado, igualmente, o Colóquio Engels: bicentenário do nascimento na Faculdade de Letras da Universidade de Lisboa organizado pelos professores José Barata-Moura, Jorge Velázquez Delgado e João Quartim de Moraes. O canal Tutaméia fez uma longa entrevista com José Paulo Netto sobre as produções de Engels. Outras iniciativas, como por exemplo as lives do Coletivo Marxista da Rural (MAR/UFRRJ) e da Rede de estudos em relações internacionais e marxismo (RIMA), também promoveram debates sobre a importância de Engels na tradição marxista contemporânea.

O dossiê Engels 200 Anos da Germinal: Marxismo e Educação em debate reúne um conjunto de produções que analisam diferentes aspectos da trajetória, das suas contribuições, tanto mais gerais, como específicas ao marxismo e ao pensamento teórico e científico em geral. A seção Debate abre com dois artigos que abordam aspectos gerais da sua obra e trajetória intelectual: o primeiro "O jovem Engels: vida e 
obra" de Jales Dantas da Costa investiga a trajetória do jovem Engels, do seu complexo processo de amadurecimento intelectual relacionado a práxis revolucionária até chegar a uma posição materialista e de defesa do comunismo proletário. O segundo artigo, "Engels: pensador maiúsculo", de Mauro Castelo Branco de Moura, procura resgatar a dimensão de Engels como um pensador original, independente da sua colaboração com Marx, fazendo desta maneira uma plena justiça a sua importância como intelectual e revolucionário.

Seguem-se dois artigos dedicados a aspectos teórico-metodológicos da obra do nosso homenageado e do marxismo: o de Claus Magno Germer "O método materialista e dialético de Marx e Engels" que tem por objetivo expor o método da economia política, em sua estreita articulação com o método de pesquisa geral, fundado no materialismo filosófico e na dialética e a partir dos escritos dos revolucionários alemães, identificar o que constitui o método marxista. Por sua vez, André Figueiredo Brandão, em seu escrito "Friedrich Engels e a questão do método no marxismo", analisa criticamente a concepção e a contribuição de Engels para a elaboração do método marxista, procurando destacar a existência de uma tensão entre "uma visão codificada e apriorística do marxismo; e uma forma mais acurada de encarar o seu modo de ser, enquanto um método que busca extrair as suas resoluções do próprio movimento do objeto."

Os três artigos seguintes abordam aspectos da concepção materialista da história, da história econômica e a concepção do desenvolvimento histórico da humanidade, em Engels. O primeiro de Osvaldo Coggiola, "O materialismo histórico" analisa os aspectos mais gerais da "crítica social moderna" elaborada por Marx e Engels. Ligia Osorio Silva, "Três contribuições para a história econômica medieval" destaca as preocupações de Engels com a história econômica e, em particular, da Alemanha. O artigo analisa especificamente as noções de "revolução burguesa", fronteira e segunda servidão desenvolvidas por Engels em seus escritos As guerras camponesas na Alemanha e "A marca", Por sua vez, "Do homem ao trabalhador: implicações para a formação humana do trabalhador" de autoria coletiva de Jennifer Aline Zanela, Caroline Correia Maciel, José Milton de Lima, Margarita Victoria Rodriguez, Ângela Celeste Barreto de Azevedo e André Malina tem por objetivo identificar a contribuição da obra de Friedrich Engels para a compreensão do processo de formação humana relacionado ao desenvolvimento da humanidade, concebida a partir das relações entre o indivíduo e a natureza.

Os dois artigos seguintes analisam a obra de Engels Os princípios do comunismo e a sua contribuição ao Manifesto comunista. O primeiro de autoria de Raquel Sabará, "Os princípios do comunismo em Engels (1847): apontamentos teórico-metodológicos para além do Manifesto comunista" tem por objetivo destacar a relevância do texto, Os princípios do comunismo, de autoria de Engels, para a formulação do Manifesto comunista e de seus apontamentos teórico-metodológicos para além do panfleto de 1848 assinado juntamente com Marx. O de Júlio César Villela da Motta Filho "Em que medida Engels contribuiu para a crítica da política no Manifesto?" investiga a participação de Engels para a crítica da política elaborada no Manifesto do partido comunista, em particular a partir do seu texto Princípios do comunismo.

Os seguintes analisam um conjunto de diferentes aspectos da contribuição teórica de Engels: a questão militar, os elementos para uma teoria do imperialismo, a editoração de O capital, sobre o socialismo 
jurídico, a questão religiosa e a questão sindical. "O general de Marx: o pensamento militar de Friedrich Engels" de João Rafael Chió Serra Carvalho está voltado à análise de um relevante campo de contribuições de Engels, embora até recentemente pouco analisado entre nós, o dos seus estudos militares. $\mathrm{Na}$ continuidade Hajime Takeuchi Nozaki se ocupa no seu "O papel de Engels na editoração de O capital e sua influência na interpretação marxista sobre a crise" do debate marxista sobre o trabalho de editoração dos livros II e III de $O$ capital, em particular sobre uma possível existência de uma "teoria da crise em Marx a partir da lei da queda tendencial da taxa de lucro." Osvaldo Coggiola, por sua vez, em seu artigo "Engels e a teoria do imperialismo", procura identificar em escritos de Engels sucessivos a morte de Marx elementos que passaram a "compor as diversas teorias acerca do imperialismo contemporâneo". "Engels e o 'socialismo jurídico': apontamentos para uma crítica do Direito" de Wesley Rodrigues Sousa e Henrique Leão Coelho apresenta uma análise da contribuição de Friedrich Engels ao Direito, em particular, do seu artigo elaborado com Kautsky "Socialismo jurídico". Seguem-se dois textos sobre Engels e a religião, o primeiro "Sobre la religión como reflejo de la realidad. Una vez más en torno a la posición de Engels" de María Teresa Vila Bormey analisa a contribuição de Friedrich Engels ao problema religioso, e estabelece uma crítica a diferentes concepções, entre as quais, as que concebem o seu pensamento como mecanicista e dogmático. "Religião, política e luta de classes: as reflexões de Friedrich Engels sobre o cristianismo primitivo" de Wallace Cabral Ribeiro, procura identificar como o nosso autor trata sociologicamente a questão do fenômeno religioso e da sua articulação orgânica com a política no contexto de luta de classes.

Dando continuidade a estas diferentes contribuições, o artigo de Michelangelo Marques Torres "Alcances e limites do sindicalismo: contribuições críticas de Friedrich Engels e Karl Marx" investiga o modo como Friedrich Engels e Karl Marx analisaram a luta e a organização sindical no interior do conflito entre o capital e o trabalho, e procura demonstrar como o trabalho de Engels impactou as próprias concepções de Marx sobre esta questão.

A seção Debate se encerra com duas contribuições.: em "Libertad y necesidad en Friedrich Engels. La contribución de los escritos de Mijaíl Lifschitz de la década de 1960”, Víctor Antonio Carrión expõe a crítica desenvolvida por diferentes pensadores "marxistas ocidentais" - Sartre, Fischer e Garaudy - ao pensamento filosófico de Engels e a crítica desenvolvida de Mikhail Lifschitz àqueles teóricos. Por fim, "Engels e a crítica ao Estado como capitalista global ideal: notas sobre o planejamento e a objeção à lógica estatal", de Luiz Felipe Leão Maia Brandão, busca compreender a partir da obra de Engels o caráter de classe do Estado e estabelecer uma crítica as diferentes correntes que abandonaram uma concepção do caráter de classe, inerente ao Estado e da necessidade da sua superação através de uma via revolucionária.

$\mathrm{Na}$ seção Artigos reunimos uma série de diferentes contribuições a distintos campos da teoria marxista: teórico-metodológico, economia, política, educação e educação socialista, entre outros. O primeiro de autoria de Paulo Henrique Furtado de Araujo "Dominação abstrata. Capital: sujeito histórico", a partir de uma análise das obras de Postone, Chasin e Lukács, defende que Marx, ao criar a sua crítica da economia política a partir de 1857-58, irá transformar a sua compreensão da categoria substância e, desta maneira, altera o seu entendimento do sujeito histórico, que a partir de então será a substância automovente - o capital. Na sequênci temos Átila de Menezes Lima, em “A criação da pós-verdade e de processos de 
manipulação das massas como expressão de cortes epistemológicos da realidade e da miséria da razão", procura refletir como os "cortes epistemológicos da realidade" podem contribuir às múltiplas estratégias da direita em seus diferentes campos. Em "O uso do território no Brasil na perspectiva de uma revolução, mas qual revolução? A necessidade de uma pedagogia política”, Cláudio Jorge Moura de Castilho procura, a partir de uma abordagem materialista histórico-dialética, "analisar o processo de uso do território na perspectiva de uma revolução calcada nas condicionantes histórico-geográficas brasileiras atuais". E, como conclusão, busca mostrar que "uma revolução é um processo muito mais complexo do que se tem pensado e buscado executar a partir da academia."

Após estes artigos iniciais são reproduzidos dois artigos sobre a história do pensamento pedagógico soviético e as suas contribuições. "Sobre a questão da escola socialista: uma aproximação aos estudos de Krupskaya”, de Antonio Marley de Araújo Stedile, Viviane Alves de Oliveira Feitosa e Maria Cleide da Silva Barroso, analisa a contribuição de Nadejda Krupskaya para a luta pela emancipação da classe trabalhadora, destacando como a sua organização se desenvolve na escola, formando jovens de forma livre e inserido no interior da realidade. O segundo, "A educação brasileira à luz da concepção pedagógica de Anton Makarenko", de Samara Sales Frazão e Maria Cleide da Silva Barroso, reflete sobre a contribuição da concepção de Anton Makarenko para a educação brasileira na contemporaneidade.

$\mathrm{Na}$ sequência temos um conjunto de artigos que investiga diferentes aspectos sobre a educação e o ensino. Os dois seguintes se debruçam sobre a importância do conceito de alienação para a educação. "O conceito de alienação e o processo de reprodução da sociedade na educação" de Aline de Carvalho Moura, parte de uma discussão sobre o conceito de alienação e procura problematizar a relação entre a sociedade e a educação, pensando "como os processos educacionais reproduzem as estruturas da sociedade capitalista". "O grande ausente da educação matemática e a alienação na educação escolar", de Guilherme Wagner e Everaldo Silveira, resgata a importância do conceito de alienação para a educação matemática e para a problematização da teoria da objetivação.

A seguir, Moacir Simardi Neto no seu "As políticas neoliberais na educação: da precarização do trabalho docente e da educação pública às resistências construídas", procura analisar a implantação, pelo PSDB no estado de São Paulo, das políticas neoliberais em seus múltiplos aspectos: político-educacionais, pedagógicos e jurídicos na educação. "Educando os homens de 'mãos desarmadas': a ABCAR como aparelho ideológico do Estado" de Wallace Lucas Magalhães apresenta a "atuação da Associação Brasileira de Crédito e Assistência Rural (ABCAR) como aparelho de ideologia na construção do consenso quanto ao modelo de modernização agrária a partir da década de 1950".

O artigo de Bárbara Cristina Pupio "Indústria da cultura corporal em academias de ginástica: nexos e determinações da reestruturação produtiva na formação de professores de educação física no Brasil” analisa as relações "entre o desenvolvimento da indústria da cultura corporal no setor de academias e as disputas pela direção da formação em Educação Física no Brasil", relacionando-o com a conjuntura mais geral do neoliberalismo e da reestruturação produtiva. "Em defesa do realismo no ensino de Geografia", Rafael Rossi analisa as contribuições da pedagogia histórico-crítica e das elaborações de Lukács para uma defesa do realismo no ensino de Geografia. 
$\mathrm{Na}$ sequência são problematizados temas sobre a pandemia do novo coronavírus: "As contradições sociais evidenciadas pelo novo coronavírus e a vida das mulheres no contexto de pandemia", de Ariana Rocha Caldeira e Nívia de Morais Bispo, avalia como a pandemia do novo coronavírus "revela e potencializa as contradições da sociedade capitalista, que mostra a sua face mais destrutiva: o lucro acima das vidas" e como impacta, em particular, as mulheres com o crescimento dos índices de violência contra mulher e de feminicídio. "Discurso sedutor sobre o ensino remoto e professores e professoras de ciências naturais: adesão ou resistência?” de Flávio Henrique Chaves Filho, Hinan Tsai Sun, Elaine Cristina Santos da Silva e Luciana Maria Lunardi Campos procura "analisar o posicionamento de professores/as da área de Ciências da Educação Básica perante afirmações relativas ao ensino remoto no contexto da pandemia do COVID-19."

"Modernização em cantos: o sistema cultural na fórmula goianidade" de Álcio Crisóstomo Magalhães busca analisar como o "sistema cultural na fórmula goianidade corresponde à demonstração de como os processos sociais nascidos da modernização em Goiás criam uma experiência civilizatória" a partir da construção de Goiânia, da "organização de suas primeiras organizações culturais (Instituto Histórico e Geográfico de Goiás, Academia Goiana de Letras, rede pública de ensino). A seção se encerra com o artigo "Política educacional de Pernambuco, regulação e gerencialismo: criando nexos psicofísicos para modificação do trabalho docente" de Rosângela Cely Branco Lindoso e Ana Lucia Felix dos Santos procura, partindo de Gramsci "debater relações de articulação entre a política educacional pernambucana e o gerencialismo como técnica de trabalho, enquanto nexos psicofísicos".

Na seção Documentos são reproduzidos dois textos de Friedrich Engels: o primeiro reúne uma série de quatro artigos sob o título "O debate sobre a Revolução em Berlim” publicado nos números 14, 15, 16, 17 da Nova Gazeta Renana de 14 a 17 de junho de 1848. Este texto impresso no jornal Nova Gazeta Renana foi traduzido por Lívia Cotrim e vem acompanhado de uma apresentação de Vera Cotrim e Ana Cotrim, que destacam o importante trabalho de investigação realizado por Lívia sobre o jornal revolucionário alemão. O segundo, "Pode a Europa se desarmar?”, foi escrito por Engels em fevereiro de 1893 e publicado no periódico social-democrata Vorwärts um mês depois e, o seu prefácio de 28 de março por ocasião do seu aparecimento sob a forma de panfleto. A tradução é assinada por João Rafael Chió Serra Carvalho, que também apresenta um conjunto de notas recheadas de informações.

Na seção Entrevista apresentamos uma entrevista com Muniz Gonçalves Ferreira, professor da Universidade Federal Rural do Rio de Janeiro (UFRRJ) sobre a sua trajetória intelectual, militância política e, em particular, seus estudos sobre Engels divulgados na forma de organização de livros, capítulos de livros e artigos em revistas acadêmicas e políticas.

A última seção - Resenhas - reúne três contribuições, as duas primeiras dedicadas a uma biografia de Karl Marx e as traduções de $O$ capital em língua espanhola. Em sua resenha "Karl Marx uma biografia dialética", Daniel de Souza Lemos faz uma análise do livro de Angelo Segrillo Karl Marx: uma biografia dialética que teve a primeira edição em 2018 e foi reeditada em 2019. Daniel Lúcio Petronzelli, por sua vez, apresenta o livro do historiador argentino Horácio Tarcus: La Biblia del proletariado. Traductores y editores de El Capital en el mundo hispanohablante publicado na Argentina em 2018. E, por fim, a escrita por Leonardo Carlos de 
Editorial

Andrade "Para entender a escola do trabalho" do livro de 2018 de autoria Caio Antunes: A escola do trabalho: formação humana em Marx.

Assim, com esta edição, a revista Germinal junta-se a todas as iniciativas dedicadas a homenagear e a render tributos, ao longo deste ano de 2020, a Friedrich Engels. Passados 200 anos do seu nascimento, Engels sobressai pela sua vida, obra teórica e militância revolucionária. Viva Engels! Boa leitura a todas e todos.

\section{Notas}

${ }^{1}$ Professora do Programa de Pós-Graduação em Educação (PPGE) da Universidade Tuiuti do Paraná (UTP). Dra. em Filosofia e História da Educação - UNICAMP. Líder do Grupo de Pesquisa/CNPq Trabalho, Educação e Políticas Educacionais/Linha Formação de Professores. Plataforma Lattes: http://buscatextual.cnpq.br/buscatextual/busca.do Orcid: https://orcid.org/00000002-8511-2313 E-mail: maria.pereira@utp.br

2 Doutor em "Ciências Humanas na área da Filosofia" pela Universidade de Varsóvia. Professor do PPGEd-UTP e do Curso de História da Universidade Tuiuti do Paraná. Membro dos Grupos de Pesquisa: CAPITALISMO E HISTÓRIA - Instituições, Cultura e Classes Sociais - UFG; Grupo de Estudos e Pesquisas Marxismo e Políticas de Trabalho e Educação - MTE HISTEDBR - UFBA; Pensamento social, intelectuais e circulação de idéias - UFPR; Políticas públicas e gestão da educação - UTP; Trabalho, Educação e Políticas Educacionais (TEPE/UTP)- https://www.tepeutp.com.br/ - UTP. Plataforma Lattes: http://lattes.cnpq.br/8913925209981626 Orcid: https://orcid.org/0000-0001-5377-6468 E-mail: pedro.costa@utp.br

3 Professor da Escola de Serviço Social da Universidade Federal do Estado do Rio de Janeiro (Unirio). Doutor em Serviço Social pela UFRJ. Membro da coordenação colegiada do Grupo de Trabalho sobre teoria marxista da dependência da Sociedade Brasileira de Economia Política (SEP) e do Coletivo do Laboratório de Ensino, Pesquisa e Extensão sobre Estado, movimentos sociais e acumulação capitalista (Cepemac) da Unirio. Plataforma Lattes: http://lattes.cnpq.br/9080597950497381. Orcid: https://orcid.org/0000-0002-8927-1055. E-mail: rodrigo.castelo@unirio.br.

Recebido em: 31.12 .2020

Aceito em: 31.12.2020 